\title{
PELATIHAN PEMBUATAN MEDIA PEMBELAJARAN UNTUK PERWAKILAN GURU SMU MUHAMMADIYAH SE DIY PADA MAJELIS PUSTAKA DAN INFORMASI (MPI) PWM DIY
}

\author{
Oleh: \\ Arfiani Nur, Khusna Lisna, Zahrotun Rusydi Umar \\ Universitas Ahmad Dahlan Yogyakarta

\section{Ringkasan}

Pada era persaingan global saat ini, ilmu pengetahuan dan teknologi berkembang begitu pesat melalui berbagai inovasi-inovasi yang semakin maju seiring dengan perkembangan zaman. Majelis Pustaka dan Informasi (MPI) PWM DIY merupakan majelis ditingkat wilayah dan dibawah MPI PP Muhammadiyah mempunyai program kerja salah satunya mengembangkan dan meningkatkan serta menciptakan daya saing civitas terutama guru Muhammadiyah sehingga tercipta pengajar yang unggul disertai pemanfaatan teknologi untuk peningkatan kualitas belajar dan menunjang pembelajaran. Agar program kerja dari MPI PP Muhammadiyah dapat berjalan dengan lancer maka dilakukanlah pelatihan pembuatan media pembelajaran untuk perwakilan Guru SMU Muhammadiyah se DIY. Metode yang digunakan dalam pelatihan ini adalah dengan memberikan modul pelatihan, bimbingan dengan cara tutorial, pemberian contoh dan studi kasus dan yang terakhir adalah evaluasi. Dari evaluasi yang dilakukan menggunakan kuesiner dalam pelatihan ini dihasilkan bahwa kemampuan dari peserta naik $10 \%$ yaitu kemampuan dari sebelum pelatihan $59,82 \%$ setelah pelatihan menjadi 70,57\%. Sehingga pelatihan ini dapat dikatakan berhasil karena dapat meningkatkan kemampuan dari peserta dalam membuat media pembelajaran

Kata Kunci: Media Pembelajaran, MPI

\begin{abstract}
In the current era of global competition, science and technology are growing so rapidly through innovations that are progressing along with the times. Library Assembly and Information (MPI) PWM DIY is a regional level assembly and under the MPI PP Muhammadiyah has a work program one of them to develop and improve and create civitas competitiveness especially teachers Muhammadiyah so as to create a superior teacher with the use of technology to improve the quality of learning and support learning. In order for the work program of MPI PP Muhammadiyah to run smoothly then conducted training of learning media making for representatives of Teacher of SMU Muhammadiyah se DIY. The method used in this training is to provide training modules, tutorial guidance, sampling and case studies and the last one is evaluation. From the evaluation conducted using the questionnaire in this training resulted that the ability of the participants increased by $10 \%$ ie the ability from before training $59.82 \%$ after training to $70.57 \%$. So this training can be said successful because it can improve the ability of the participants in making learning media
\end{abstract}

Keywords: Learning Media, MPI

\section{A. PENDAHULUAN}

\section{Latar Belakang}

Pada era persaingan global saat ini, ilmu pengetahuan dan teknologi berkembang begitu pesat melalui berbagai inovasi-inovasi yang semakin maju seiring dengan perkembangan zaman. Kemajuan di dalam bidang pengetahuan dan teknologi telah 
memberikan pengaruh besar terhadap bidang pendidikan. Banyak di kalangan pendidik yang sudah menggunakan media informasi dan multimedia dalam melakukan pembelajaran. Karena dengan menggunakan media pembelajaran siswa tidak cepat bosan dan dapat dapat mempelajari kembali dengan mudah di rumah.

Majelis Pustaka dan Informasi (MPI) PWM DIY merupakan majelis ditingkat wilayah dan dibawah MPI PP Muhammadiyah mempunyai program kerja salah satunya mengembangkan dan meningkatkan serta menciptakan daya saing civitas terutama guru Muhammadiyah sehingga tercipta pengajar yang unggul disertai pemanfaatan teknologi untuk peningkatan kualitas belajar dan menunjang pembelajaran. Hal ini disebabkan masih minimnya guru-guru pada sekolah muhammadiyah yang memiliki kemampuan dalam memebuat media pembelajaran.

Berdasarkan permasalahan yang terjadi pada anggota anggota Majelis Pustaka danInformasi (MPI) PWM DIY, maka dilakukan pelatihan pembuatan medi pembelajaran untuk anggota Majelis Pustaka dan Informasi (MPI) PWM DIY. Dengan kegiatan pelatihan melalui pengabdian masyarakat ini diharapkan dapat memberikan kontribusi dalam peningkatan kualitas belajar di SMU Muhammadiyah yang berbasis TIK sehingga diharapkan program kerja serta visi misi pembelajaran di SMU Muhammadiyah dapat tercapai.

\section{Tujuan}

Berdasarkan uraian rumusan masalah diatas, maka pelatihan ini mempunyaii tujuan yaitu:

a. Mengenalkan Macromedia Flash kepada perwakilan guru SMU Muhammadiyah se-DIY.

b. Memberikan pemahaman tentangpembuatan media pembelajaran interaktif menggunakan Macromedia Flash.

c. Sebagai fasilitator dalam pembuatan media pembelajaran menggunakan Macromedia Flash.

d. Memberikan pemahaman peanfaatan teknologi informasi dan komunikasi dalam pendidikan.

\section{B. METODE YANG DITERAPKAN}

Metode yang diterapkan dalam pelatihan ini adalah:

1. Pemberian modul kepada peserta, sehingga peserta lebih mudah dalam menerima dan memahai materi yang diberikan, sehingga kegiatan ini lebih efektif.

2. Tutorial, dalam kegiatan ini peserta diberikan bimbingan tutorial untuk praktikum membuat media pembelajaran.

3. Pemberiancontohdankasus permasalahan, sehingga diharapkan peserta akan lebih paham dalam membangun/membuat media pembelajaran.

4. Dilakukan evaluasi hasil pembuatan aplikasi dan dipraktekkan pada media pemebelajaran seseuai dengan mata pelajaran yang di ampu 
Diterbitkan oleh Lembaga Pengabdian kepada Masyarakat

Universitas Ahmad Dahlan Yogyakarta

\section{HASIL DAN DAMPAK}

\section{Hasil Pelatihan}

Pelaksanaan pelatihan ini dibantu oleh 4 asisten yang terdiri dari 4 mahasiswa. Pelatihan ini berlangsung selama 3 hari yang terdiri dari 6 materi yaitu:

a. Pengenalan Macromedia Flash

b. Pengenalan Objek dalam Macomedia Flash

c. Pembuatan Animasi pada Macromedia Flash

d. Mengimport Gambar dan Vidio ke Macromedia Flash

e. Membuat Button pada Macrommedia Flash

f. Membuat Soal dan Evaluasi pada Macromedia Flash

Pada saat pelatihan peserta meskipun hanya sedikit namun terlihat antusias mengikuti rangkaian pelatihan. Dokumentasi pelatihan ditunjukkan dalam Gambar 1 dan Gambar 2.

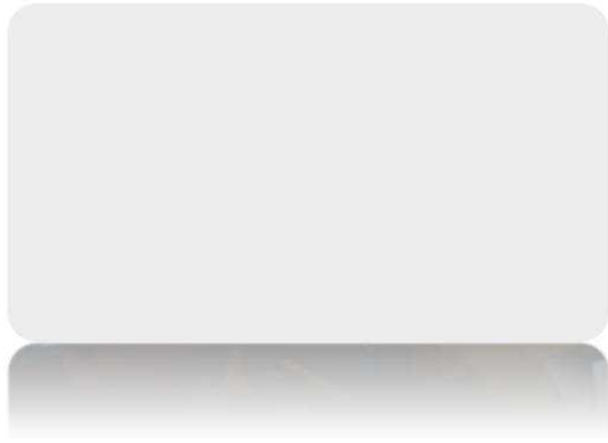

Gambar 1. Dokumentasi pelatihan

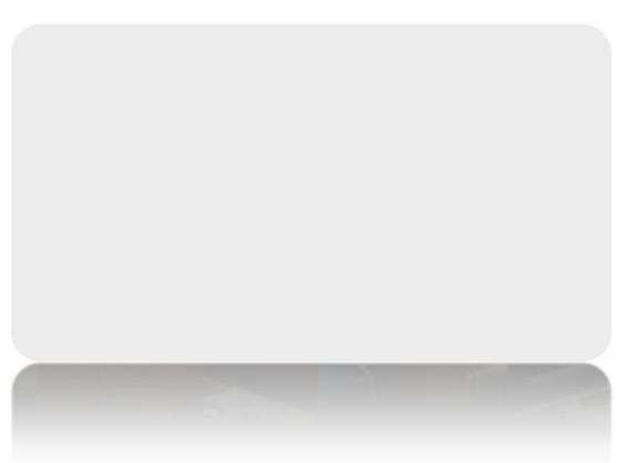

Gambar 2. Proses Pelatihan

Dalam pelatihan ini dilakukan analisis kemampuan peserta menggunakan Adapun penjelasan kuesioner adalah sebagai berikut:

\section{Kuesioner sebelum pelatihan}

Kuisoner ini bertujuan untuk mengukur kemampuan peserta pelatihan sebelum mengikuti pelatihan Media Pembelajaran Menggunakan Macromedia Flash.

$$
\text { Berdasarkan hasil kuisoner sebelum }
$$




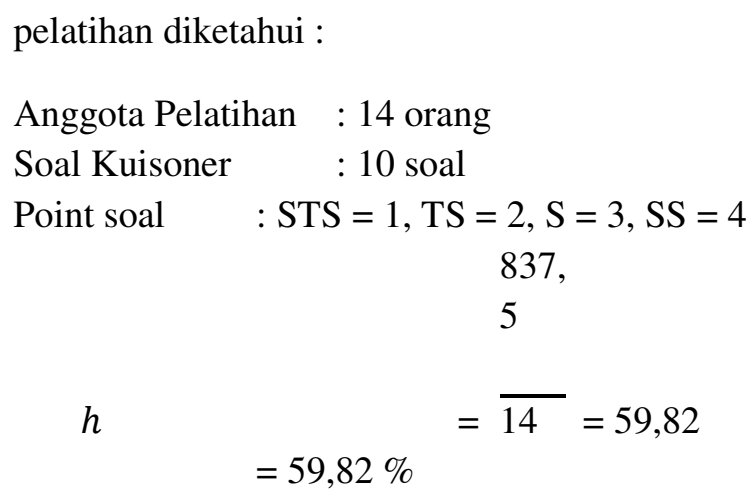

\section{Kuesioner sesudah pelatihan}

Kuisoner sesudah pelatihan bertujuan untuk melihat perkembangan kemampuan dari anggota pelatihan. Kuisoner ini dapat membandingkan antara kemampuan peserta pelatihan sebelum dan sesudah mengikuti pelatihan serta dapat melihat tingkat keberhasilan dari pelatihan Media pembelajaran Menggunakan Macromedia Flash.

Berdasarkan hasil kuisoner sesudah pelatihan diketahui:

$$
\begin{aligned}
& \text { Anggota Pelatihan : } 14 \text { orang } \\
& \text { Soal Kuisoner : } 10 \text { soal } \\
& \text { Point soal } \quad: \text { STS }=1, \mathrm{TS}=2, \mathrm{~S}= \\
& 3, \mathrm{SS}=4 \\
& 917, \\
& h \quad h=\quad \overline{13} \\
& =70,57=70,57 \%
\end{aligned}
$$

Dari hasil analiais kuesioner sebelum dan sesudah pelatihan maka dapat dilihat bahwa kemampuan dari peserta naik $10 \%$. Sehingga pelatihan ini dapat dikatakan berhasil karena dapat meningkatkan kemampuan dari peserta dalam membuat media pembelajaran

\section{Hasil media pembelajaran peserta}

a. Doni Oktama (mengenal sistem operasi)

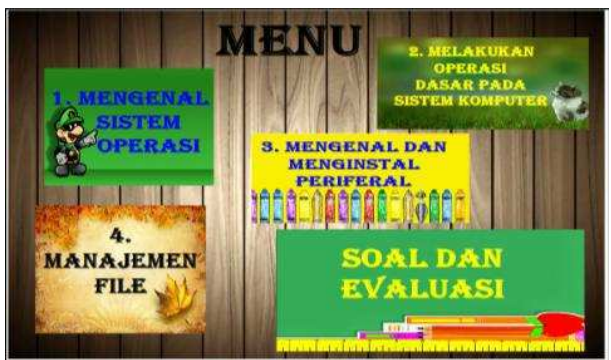

Gambar 3. media pembelajaran doni oktama 
Diterbitkan oleh Lembaga Pengabdian kepada Masyarakat

Universitas Ahmad Dahlan Yogyakarta

b. Muhammad Yasin (akhlak)

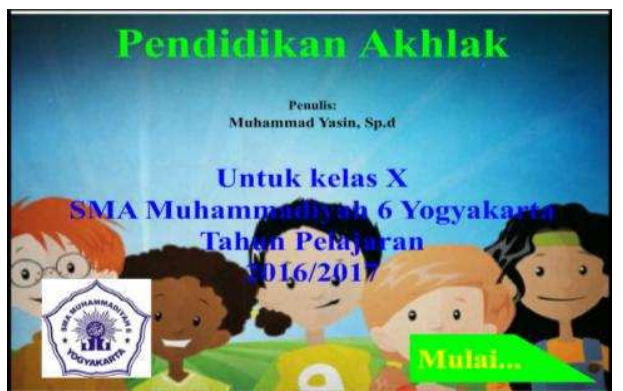

Gambar 4. Media pembelajaran Muh. Yasin

c. Luluk Linawati ( makanan dan sistem pencernaan)

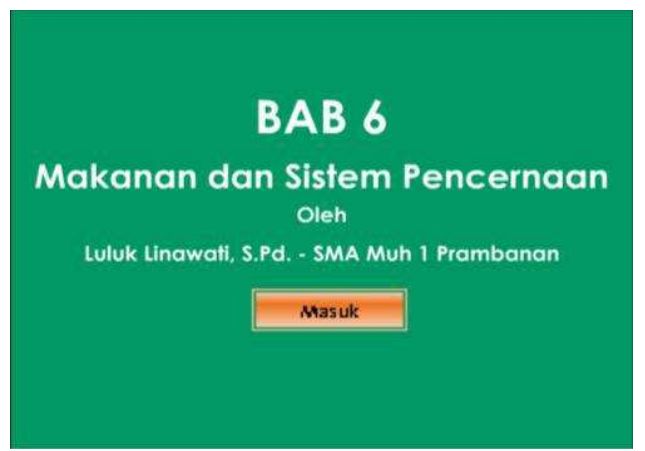

Gambar 5. Media Pembelajaran luluk linawati

d. Sukir (larutan penyangga kimia)

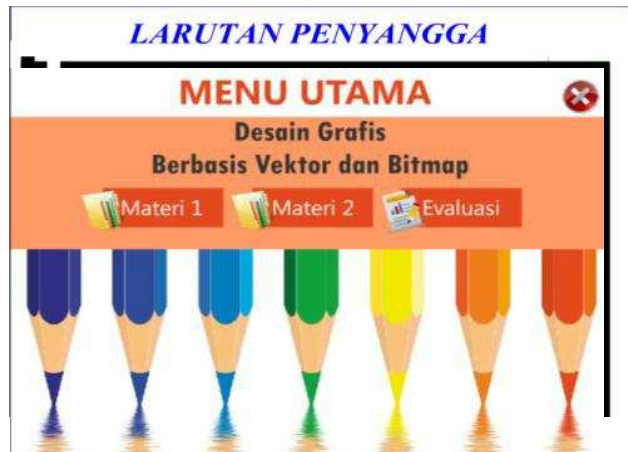

Gambar 6. Media Pembelajaran sukri

e. Annisa Nur I.S (desain grafis berbasis web dan bitmap)

Gambar 7. Media Pembelajaran Annisa 
f. Taufik Hidayat (ppkn)

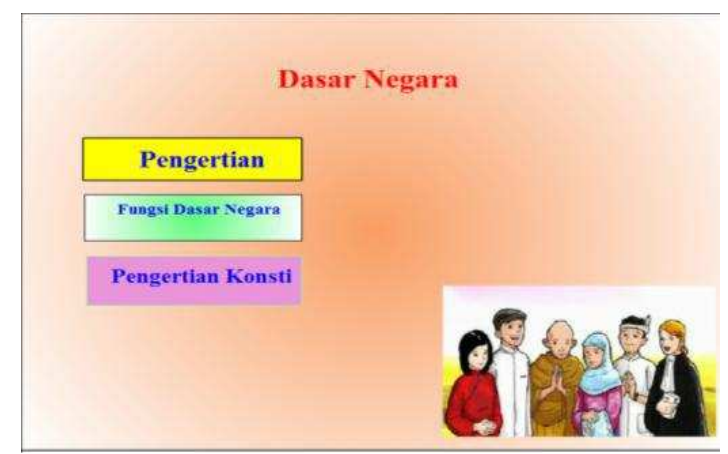

Gambar 8. Media Pembelajaran Taufik Hidayat

\section{Dampak Pelatihan}

Dampak diadakannya pelatihan pembuatan media pembelajaran Macromedia Flash ini yaitu:

a. Bagi Majelis Pustaka dan Informasi Pimpinan Wilayah Muhammadiyah Daerah Istimewa Yogyakarta dapat mengembangkan dan meningkatkan serta menciptakan daya saing civitas terutama guru SMU Muhammadiyah Yogyakarta sehingga tercipta pengajar yang unggul disertai pemanfaatan teknologi untuk peningkatan kualitas belajar dan menunjang pembelajaran.

b. Meningkatnya pemahaman guru SMU Muhammadiyah Yogyakarta mengenai media pembelajaran yang lebih interaktif.

c. Dapat menerapkan teknologi dalam dunia pendidikan berupa media pembelajaran interaktif untuk proses belajar mengajar.

d. Para anggota Majelis Pustaka dan Informasi (MPI) PWM DIY yang terdiri dari guru-guru pada sekolah muhammadiyah

e. Para Guru-guru mendapatkan pengetahuan dan ketrampilan tambahan khususnya dalam pembuatan media pembelajaran

f. Para peserta dapat mengembangkan kemampuan untuk membuat media pembelajaran sesuai dengan mata pelajaran yang di ampu.

\section{WAKTU PELATIHAN}

Pelatihan pembuatan media pembelajaran menggunakan Macromedia flash dilaksanakan selama 2 hari pada tanggal 30 dan 31 januari 2017, dimulai dari pukul 09.00 WIB hingga pukul 14.00 WIB. 
Diterbitkan oleh Lembaga Pengabdian kepada Masyarakat

Universitas Ahmad Dahlan Yogyakarta

\section{E. LOKASI PELATIHAN}

Lokasi pelatihan Macromedia Flash ini dilaksanakan yaitu di Laboratorium komputasi dasar Kampus 3 Universitas Ahmad Dahlan Yogyakarta. Penyajian pada peta Kampus 3 Universitas Ahmad Dahlan Yogyakarta:

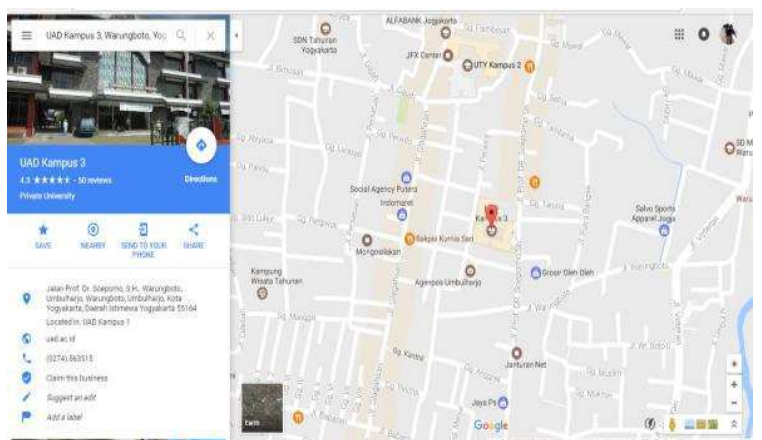

Gambar 7. Peta Kampus 3 Universitas Ahmad Dahlan

\section{F. KENDALA}

Pada saat pelatihan, dari total peserta yang berjumlah 25 orang/sesi tidak dapat mengikuti pelatihan dengan optimal, dikarenakan ada kegiatan lain, tidak fokus dan tidak konsisten di setiap kehadiran. Peserta yang hadir mengikuti pelatihan hanya 15 orang. Pada saat pelatihan berlangsung terdapat beberapa kendala yaitu:

1. Karena rentang usia dari peserta yang berbeda-beda menyebabkan pelatihan kurang maksimal.

2. Jarak rumah peserta yang jauh sehingga peserta pelatihan tidak dapat maksimal 25 orang

\section{G. PENUTUP}

\section{Kesimpulan}

Berdasarkanpelatihan yangtelah dilaksanakan, maka dapat diperoleh kesimpulan:

a. Telah dihasilakan modul pelatihan pembuatan media pembelajaran menggunakan macromedia flash sebagai acuan perserta dalam membuat media pembelajaran.

b. Pelatihan pembuatan media pembelajaran menggunakan macromedia flash dilaksanakan sebanyak 2 kali pertemuan dalam 2 hari.

c. Dari hasil evaluasi, dinilai peserta pelatihan yang dapat membuat media pembelajaran menggunakan macromedia flash serta memahami tentang software macromedia flash sebanyak $40 \%$. 


\section{Saran}

Saran yang dapat disampaikan dari hasil Pelatihan yang telah dilaksanakan adalah:

a. Pelatihan pembuatan media pembelajaran dengan menggunakan macromedia flash, sebaiknya jangka waktu pelatihan diperpanjang agar peserta dapat memahami lebih dalam tentang materi yang diberikan.

b. Pembuatan modul pelatihan media pembelajaran menggunakan macromedia flash masih perlu diperbaiki, karena terdapat beberapa materi yang belum tersampaikan di dalam modul pembuatan media pembelajaran menggunakan macromedia flash. 